\title{
FROM A NEW WORKPLACE TO A NEW WAY OF WORKING: LEGITIMIZING Organizational Change ${ }^{1}$
}

\author{
Grégory JEMINE \\ HEC - Management School - Université de Liège \\ Christophe DUBOIS \\ Faculty of Social Sciences - Université de Liège \\ François PICHAULT \\ HEC - Management School - Université de Liège
}

${ }^{1}$ This paper is a self-archived version of an original article. Please use the following reference for citing: Jemine, G., Dubois, C., \& Pichault, F. (2019). From a New Workplace to a New Way of Working: Legitimizing Organizational Change. Qualitative Research in Organizations and Management, 15(3), 257-278.

Purpose - Several studies have recently documented projects of organizational transformation and modernization which, commonly clustered under the umbrella term "New Ways of Working" (NWoW), simultaneously entail material, technological, cultural and managerial dimensions. Academic contributions, however, have paid little attention to the mechanisms allowing such projects to progressively become legitimized in organizational discourses and practices. The paper aims to investigate the distinctive features of the legitimation process underlying the implementation of NWoW projects.

Methodology - The paper relies on a longitudinal, three-year analysis of a large insurance company. Data were collected through qualitative methods including semi-structured interviews (48), periods of observation (3 months), and document analysis (78).

Findings - The paper develops a grounded and integrative framework of legitimation processes underlying "NWoW" change projects. The framework emphasizes four decisive operations of translation in "NWoW" design and implementation: translating material constraints into strategic opportunities; translating strategic opportunities into a quantitative business plan supported by the top management; translating compelling discourses around "NWoW" into an organizational machinery; translating a transformation project into discourses of unequivocal success, conveyed by legitimate spokespeople within and beyond the organization.

Originality - Besides contributing to the understanding of a managerial fashion which has received little academic attention so far, the paper also offers an original integrative framework to account for legitimation processes that combines two theoretical approaches - the sociology of translation and research on institutionalist work.

Keywords - Legitimation process, new ways of working, organizational change, sociology of translation, institutional work 


\section{INTRODUCTION}

In recent years, several third-sector companies have claimed to modernize by implementing "New Ways of Working" (NWoW) projects. NWoW appears as a fashionable and loosely defined label used by managers and consultants to promote a shift from an "old" to a "new" way of working ${ }^{1}$. As such, NWoW inherently carries a logic of change that is supposedly cultural, technological, material and managerial at the same time (De Leede, 2017; Kingma, 2018). Although abundant managerial literature on the topic has bloomed in the last fifteen years ${ }^{2}$, grounded academic contributions on NWoW have remained scarce (De Leede, 2017). Existing scientific literature often focuses on specific issues in visible and stabilized NWoW environments, such as flexibility in time and space (Vink et al., 2012), knowledge sharing (Kok et al., 2015) or managerial control (Sewell and Taskin, 2015). However, these contributions have not questioned the taken-for-granted nature of NWoW and have systematically overlooked the mechanisms allowing such projects of transformation to progressively become legitimized in organizational discourses and practices. As a result, little is known about how the normative discourses and ideas embedded into the NWoW management fashion are progressively turned into material workspaces and accepted elements of organizational life.

To address this issue, the research question raised in the paper is the following: how do "NWoWlabelled" change projects become legitimate in organizational contexts? The paper assumes that NWoW is first and foremost a management fashion (Abrahamson, 1996) from which actors in organizations draw in order to initiate and conduct projects of organizational change. These "NWoW projects", in turn, undergo a process of legitimation by which various actors attempt to present NWoW as a desirable solution for the organization and its members. The paper precisely aims to study the legitimation process underlying change projects bearing the "NWoW" label. While organizational change has been widely studied and repeatedly theorized, the issue of legitimation has not received the same level of attention so far. To account for the legitimation of a NWoW change project, the paper builds on two well-established models of change - Greenwood, Suddaby and Hinings' model of institutional change (2002) and Callon's model of translation (1986). These models are rooted in two respective theoretical approaches - institutional work on the one hand and the sociology of translation on the other - which offer conceptual insights on legitimation work and legitimation processes of NWoW projects. The contributions of the paper are twofold: on the empirical level, it shows that NWoW consists of organizational change projects supported by a legitimation process. On the theoretical level, it investigates the issue of legitimation in organizational change by exploring the interrelationships between two models of change that have rarely been used together.

\section{NWOW AS A LEGITIMATION PROCESS}

\section{The origins of "New Ways of Working"}

New Ways of Working may be viewed as a management fashion that was developed over the last two decades by Dutch consulting companies and that was popularized through the seminal book of Erik Veldhoen, entitled "The Art of Working" (2005). As multiple organizations such as Microsoft Netherlands, Rabobank Netherlands, or the Belgian Federal Public Service of Social Security committed to large-scale projects bearing the "NWoW" label (Bijl, 2011), the fashion began to attract the interest of researchers and academics from various fields of research, such as organizational psychology (Ten Brummelhuis et al., 2012), management (Assarlind et al., 2013), human resources (Peeters, 2014), and architecture (De Bruyne and Gerritse, 2018). Promoters of NWoW assume organizations to be old- 
fashioned and inadequately equipped to face an ever-changing world, and encourage them to change (or to "modernize") their workspaces, working tools, and managerial culture (Bijl, 2011; Veldhoen, 2005). To date, the academic literature mostly developed essentialist definitions of New Ways of Working, built around fixed and given sets of measures and practices. For instance, NWoW has been defined as an "approach of work" promoting work-time flexibility, spatial flexibility, and new media technologies (Demerouti et al., 2012; Ten Brummelhuis et al., 2012). For Ajzen and colleagues (2015), NWoW rather refers to flexible spatiotemporal practices, collaborative work practices, and participative management. In another version, NWoW is depicted as a "concept" entailing time and location independent work, output-based management, knowledge accessibility, flexible working relations, and an open workplace (Gerards et al., 2018). Aside from the fact that these definitions do not entirely overlap with each other, one of their major limitations is to confine NWoW to a series of common "dimensions" or "measures", hence reifying the managerial object of interest rather than deconstructing it. By contrast, the paper suggests avoiding any essentialist definition of NWoW and problematizing NWoW as being projects of organizational change involving practices aimed at legitimizing the NWoW fashion.

The questions related to the adoption, the design and the deployment of NWoW projects remain grey areas in the literature. Studies recognize the development of a management fashion and have been able to pinpoint its foundational books and texts on the one hand (Kingma, 2018), and have offered insights on the effects and consequences of NWoW environments on employees (Demerouti et al., 2012; Gerards et al., 2018), managers (Sewell \& Taskin, 2015), and organizations (De Leede, 2017; Kingma, 2018) on the other hand. What happens in between, however, remains vastly underexplored. Especially, there is at the present time no study investigating how the NWoW fashion is gradually acquiring legitimacy in various organizational contexts. Existing studies have little to say on how NWoW manages to "travel" (Czarniawska, 1996) from management books and consultancy firms to organizations, on how it is turned into large-scale organizational change projects involving workspace redesign, new working tools, and attempts to redefine management, governance, and organizational culture. The paper, therefore, conceptualizes New Ways of Working as projects of organizational change involving a process of legitimation.

\section{Organizational change as a legitimation process}

Over the years, numerous theories of organizational change have been developed. Demers (2007) has suggested distinguishing between rational theories - which include, for instance, contingency theories (Donaldson, 2001) and resource dependency theories (Salancik and Pfeffer, 1977), imitation and selection theories such as the new institutionalism (Di Maggio \& Powell, 1983), and transformational approaches that might be configurational (Mintzberg, 1979), cognitive (Weick, 1979), or political (Crozier and Friedberg, 1980). However, not all of these approaches have explicitly underlined the role of legitimation processes and legitimacy in organizational change. Four theoretical perspectives constitute an exception to this observation. First, the contingency theories have been interested in exploring legitimacy as the result of a permanent "quest" undertaken by organizations to meet the expectations of the social system they are a part of (Dowling and Pfeffer, 1975). Second, the search for legitimacy has been described as a core explanans of the new institutionalism, in which legitimation often equates mimicking other organizations (Pedersen and Dobbin, 2006). Third, institutional work has been interested in the study of the practices aimed at creating legitimacy in the course of change projects (Lawrence and Suddaby, 2006). Finally, the sociology of translation has viewed the 
construction and the sustaining of legitimacy as an essential issue in change processes (Akrich et al., 2002; Callon, 1986).

This study draws on two "transformational" approaches (Demers, 2007) that are the institutional work and the sociology of translation. Both perspectives share a common view of organizations as being "made of processes" (Langley et al., 2013, p. 4) and adopt a common conception of the organizational actors, depicted as rational and political. Legitimation is viewed as a process of construction by which organizational actors, through the "work" they do, contribute to make sense of the innovations and manage to "grow" in importance (Callon and Latour, 1981; Lawrence and Suddaby, 2006). By contrast, contingency theories and the new institutionalism have developed a conception of legitimacy as being a stable property of organizations - which have to "be legitimate" in front of their "audiences" - or of ideas - which, if legitimate, may justify organizational change (Dowling \& Pfeffer, 1975; Suchmann, 1995). Insofar as the paper is primarily interested in legitimation processes, it will retain the institutional work and the sociology of translation as conceptual frameworks of interest. More specifically, the paper will build on two models of change deriving from these perspectives: the sixstep framework of Greenwood and colleagues (2002) and the four-step model of Callon (1986). The two theoretical perspectives, as well as the two selected models, are introduced below.

\section{Legitimation, institutional work and the sociology of translation}

Looking into how legitimacy is progressively built over time has been a major concern of research on "institutional work" (Lawrence and Suddaby, 2006). In this approach, legitimation refers to the process through which new organizational arrangements gradually appear as desirable and suitable for the organization in the eyes of its members (Dacin et al., 2002). Research on institutional work acknowledges the importance of the work performed by competent actors - or "agents of legitimacy" (Dacin et al., 2002, p. 47) - who are able to influence the members of an organization through action (Garud et al., 2007; Lawrence and Suddaby, 2006; Perkmann and Spicer, 2008). Legitimation may, therefore, be understood as a fundamentally oppositional and political process involving actors with their own interests who deploy strategies aimed at altering their organizational contexts, for the purpose of building acceptance around change projects (Hwang and Colyvas, 2011; Lawrence and Suddaby, 2006; Zietsma and Lawrence, 2010).

The model of Greenwood et al. (2002) is used in the present paper precisely to investigate the role of specific actors in legitimating change, by examining how questionable ideas become taken-for-granted conceptions that can survive and persist through time. The model is structured around six stages characterizing change - precipitating jolts, deinstitutionalization, pre-institutionalization, theorization, diffusion, and reinstitutionalization. It assumes that organizational change is triggered by "precipitating events" that destabilize the organizations and make it possible for specific actors to develop a rhetoric of change. These actors then commit to a work of "deinstitutionalization" that consists of deconstructing and reframing the existing situation, and design or "pre-institutionalize" technically viable solutions for the organization. These solutions, according to the model, have to be turned into imperatives for change through means of theorization - a process consisting in facilitating the adoption of novel ideas through abstraction (Greenwood et al., 2002, p. 60). Only then can the new practices be widely adopted and diffused, eventually becoming "natural arrangements" in the organization (Greenwood et al., 2002, p. 61). 
For its part, the sociology of translation offers analytical tools that have been widely used to study change processes in an extensive range of empirical cases (Bergström and Diedrich, 2011; Law and Callon, 1988; O'Mahoney et al., 2017). The sociology of translation views legitimation as a neverending, always unfinished process of negotiations and struggles (Akrich et al., 2002). From that perspective, the emphasis is put on "moments of translation" involving actors who, by relying on provisional sources of power, negotiate around controversies and attempt to impose their views (Callon and Law, 1982; Callon, 1986). In the course of this process, some actors manage to turn multiple elements into "black boxes", so that those elements become "things (...) that no longer need to be reconsidered" (Callon and Latour, 1981, p. 285). In that perspective, reifications or stabilizations, such as, for instance, established "NWoW workspaces" or "NWoW principles", are viewed as "costly to set up" and "fragile", and as an "artificial result based upon substantial investments" (Callon, 1998, p. 252).

Callon's model of translation suggests four stages constitutive of change processes, namely, problematization, interessement, enrolment and mobilization (1986). In the model, change is triggered by the identification of one or several problems or controversies that are presented as significant and deserving attention. Although the actors involved in the change process may act upon these problems in a variety of ways, what matters is that problematization ultimately produces indispensability, as the problems become uncontestable and need to be answered (Callon, 1986). To find solutions, further actors have to be enlisted or "interested" by the problematization, through the formation of strategic alliances around common interests and identities. Strategies are then deployed to promote particular conceptions of change and to assign roles to other actors through actions of "enrolment". Eventually, convinced "spokesmen" emerge and contribute to promote and to legitimize the change project over time.

The models of both Greenwood et al. (2002) and Callon (1986) share a similar conception of actors as being rational, active, and involved in the creation and the enactment of legitimacy within their organizational contexts. Some calls have already been made to consider these approaches as complementary and to develop integrative and empirically supported frameworks (Leca et al., 2006; Lounsbury, 2008). Following these calls, the paper aims to design an integrative framework building on these two models in order to account for legitimation processes underlying NWoW change projects. We expect this integrated framework to result in a more elaborate understanding of the case for two reasons. First, it allows to incorporate in the analysis insights from the institutional work perspective for instance on the "agents of legitimacy" and on the process of acceptance building - and insights from the sociology of translation - such as the social construction of problems and the creation of black boxes. Second, it is argued that the specific stages theorized by Greenwood et al. (2002) and Callon (1986) may usefully complement each other and result in a more thorough analysis of legitimation processes.

Consequently, relying on a qualitative, empirical, and longitudinal analysis of a single case study, the paper pursues a primary empirical ambition as well as an underlying theoretical one. Through an investigation of the legitimation process in a NWoW change project, the main objective of the paper is to contribute to the production of analytical and non-essentialist knowledge about a "management fashion" (Abrahamson, 1996) which has received little academic attention so far. Especially, there is at the present time no longitudinal and processual study on how "New Ways of Working" projects become accepted and taken-for-granted within organizations. On the theoretical level, by developing 
and testing an integrative framework building on two models of change that have rarely been brought together (Leca et al., 2006), the paper assesses the congruence between these two models on the basis of an empirical case, hence contributing more broadly to research on legitimation in organizational change.

\section{MethodOLOGY}

The present paper is based on an in-depth qualitative, empirical and longitudinal analysis of a single case study (Yin, 2011). We focus on the Belgian division of an insurance company (hereafter named "BIC") which is operating in more than sixty countries and is one of the market leaders in the "bancassurance" sector in Europe (Blondeau, 2005). Early in 2012, a strategic decision was taken at the national level among BIC top managers to commit to a large-scale transformation project that would entail multiple relocations, a redesign of the workplaces, a deployment of new technological tools and a cultural change. It was decided during the course of the process that the project would be labeled "New Ways of Working" due to its ideological proximity to existing projects in other companies that were already clustered under the same name. The relocation of the different sites of the company began in 2014 with a pilot program and a first attempt to deploy new working environments on a secondary site. Eventually, the project officially came to an end in 2017 with the relocation of BIC's headquarters. The company now actively advertises its NWoW project through multiple success stories in an attempt to position itself as a leading and innovative actor in the insurance field.

\section{Data collection}

The researchers had the opportunity to follow BIC for a period of three years (2014-2017) and to collect data through a total of three subsequent rounds that are summarized in Table 1. Initially, the researchers were granted a three-month access to the company in order to investigate the relocation and its effects on employees and managers. The access was negotiated with a senior manager of the legal protection department of the insurance company. Data collected through round one included semi-directed interviews with strategic actors in charge of the implementation of the NWoW project (12), team managers (5) and operational agents (18), in situ observations of operational teams as they were progressively transitioning to a NWoW workspace, and the analysis of internal documents supporting the change (such as training plans, presentations made to the staff, and working documents of the project teams).

The initial focus of the researchers was on discourses, practices, and interactions between the project implementers and the operational teams aiming at legitimizing visible forms of New Ways of Working. Interviews of the first round were aimed to acquire initial knowledge about the NWoW project undertaken at $\mathrm{BIC}$, its design process and its implications. The interview grid that was used in the first round was split in three parts that were (1) the emergence and the reasons of adoption of a NWoW project at BIC, (2) the implementation process of NWoW, and (3) the consequences of the project and of the relocation for the company, the departments and the employees. The two first points were especially emphasized through the interviews with project team members (12) while the latter was detailed in the interviews with employees and team managers $(23)^{3}$. Moreover, the researchers had the opportunity to sit full-time in the company's office for a period of three months, favoring their immersion in the field and allowing them to gain access to valuable information related to the project and its implications. Observations were documented in a logbook that was notably used to fine-tune our interview grids. Finally, the documents that were used in that stage were collected in an 
opportunistic way, in the course of the interviews we conducted with the actors. They notably included a forty-one page guide to the NWoW project written by the project teams for the employees, as well as several plans, roadmaps, working documents, and presentations made by the project teams, which allowed the researchers to acquire a better understanding of the NWoW project, its design and its implementation process.

While data from round one allowed to document the work accomplished by the project teams, it remained insufficient to account for the longer-term effects of the relocation. Consequently, the researchers solicited a HR representative of the company who was also a member of the project teams and obtained an agreement to conduct a second round of data collection one year later. The target of this second stage was the strategies by which the hierarchical line ( 9 interviews) seized the NWoW project and conveyed enthusiastic discourses and stories both inside and outside the organization. The managers and directors to be interviewed were selected on a voluntary basis (the researchers received nine positive answers on a total of thirty-four solicitations). In this second round, the interview grid that was used investigated (1) the motives underlying the NWoW project, (2) the involvement of team managers into the project and (3) the propensity of the interviewees to support (or to reject) NWoW. Documents such as internal surveys or presentations of surveys' results were used to strengthen our longer-term analysis of the implications and effects of the NWoW project. Round two, which was much shorter than the first, provided useful data regarding the mobilization strategies used by established spokespersons to speak in the name of other actors (Callon, 1986), thereby fine-tuning the study of the legitimation process and giving the paper a longer-term perspective.

\begin{tabular}{|l|c|c|c|}
\hline & $\begin{array}{c}\text { First round } \\
(2014 / 2015)\end{array}$ & $\begin{array}{c}\text { Second round } \\
(2016)\end{array}$ & $\begin{array}{c}\text { Third round } \\
\text { (2017) }\end{array}$ \\
\hline Observations & 3 months & 4 days & 4 interviews \\
\hline Interviews & 35 interviews & 9 interviews & 26 documents \\
\hline Documents & 44 documents & 8 documents & \\
\hline
\end{tabular}

Table 1: Data collection summary ${ }^{4}$

As the project spanned more than five years and began two years before round one was conducted, the researchers still lacked valuable information on the genesis of the program and its early phases of development - strategic discussions and negotiations occurring upstream. To overcome this drawback, a third round that included interviews with BIC's top managers, as well as analyses of working documents dating from the early years of the project, was conducted. The access to these top managers (BIC's HR Director, two strategic HR advisors, and a member of the executive committee) and strategic documents was provided by the HR Director of the company. In the last round, the researchers questioned the top managers of the organization about the adoption and design process of NWoW at the strategic level of the firm. The dataset was further expanded with various external documents containing information about the change (such as press articles, public videos, and research reports). These external documents turned out to be essential to understand how the NWoW 
project implemented at BIC managed to become a "success story" and to shine beyond the company itself.

\section{$\underline{\text { Data analysis }}$}

During the three rounds, the researchers gathered discursive accounts relative to the change process occurring at BIC. The accounts were first turned into a forty-eight pages, chronologically-ordered narrative (Czarniawska, 1995), the prime goal of which was to extensively recreate the story of the change process that spanned more than five years (2012-2017). A first round of coding and review of the interviews revealed three periods of interest in the material: the strategic planning stage (2012 to mid-2014); the first relocation to a "NWoW" building (mid-2014 to late 2014) and the short and longer term effects of the relocation (2015-2017). These three periods were used to structure the chronological account. A second round of coding was performed to identify (1) the actors, (2) their respective interests and strategies, and (3) the activities they performed and the work they did in the course of the three periods. The choice to resort to wide and generic categories for the coding process (the actors, interests, strategies, and activities) resulted from the authors' willingness to leave room for empirical surprise, unexpected findings, and creative connections (Nubiola, 2005). At the end of this cyclical process of data analysis involving back and forth between the first-hand empirical material and the chronological narrative, the researchers were able to connect their findings on the NWoW project under study with larger debates in the study of organizations around the issue of legitimation of organizational change.

The chronological document was then used to build an analytical account of the transformation project undertaken at BIC around the six-step model of Greenwood and colleagues (2002) and the four-step model of Callon (1986). To achieve this, the researchers performed an additional round of coding using the ten stages of the aforementioned models as categories. This exercise allowed them to restructure the chronological narrative around analytical and conceptual categories. In the course of the process, two stages of the model of Greenwood and colleagues (deinstitutionalization and reinstitutionalization) were left aside as they received little empirical support from the available data. The eight remaining stages were then articulated into a four-step integrative framework, as illustrated in the table below. The stages were paired together based on the arrangement and the consistency of the empirical material. Table 2 summarizes the primary data sources that were used to illustrate the four analytical moments constitutive of legitimation processes.

\begin{tabular}{|lll|}
\hline STAGES & & DATASET \\
STAGE $\mathbf{1}$ & From precipitating jolts to problematization & Third round \\
STAGE 2 & From preinstitutionalization to interessement & Third round \\
STAGE 3 & From theorization to enrolment & First round \\
STAGE 4 & From mobilisation to diffusion & Second round \\
\hline
\end{tabular}

Table 2: Analytical moments structuring the legitimation process

Each stage of the integrative framework is based on an iterative relationship between Greenwood et al.'s (2002) and Callon's (1986) models. Stage 1 accounts for the presence of destabilizing events prompting the organization to change, and posits that key actors will seize those moments to define 
problems that, according to them, have to be addressed. In stage 2, those same actors come up with potential solutions to the problems, as well as with arguments to justify the need for the company to change. They also seek potential support and attempt to establish strategic alliances. Stage 3 illustrates how those key actors deploy efforts to build local theories and convincing narratives and to enroll new actors to expand the perimeter of change. Eventually, Stage 4 reveals the mechanisms through which discourses promoting the change project are conveyed both within and beyond organizational boundaries.

Overall, data analysis was performed under two conceptual assumptions. A first of those assumptions, congruent with both Callon's (1986) and Greenwood et al.'s (2002) perspectives, is that researchers should investigate the work performed by specific actors, who are assumed to be strategic, rational, and able to alter their organizational contexts. Data analysis should thus aim to understand the "trajectories" (Czarniawska, 2003) or "translations" (Callon, 1986) of ideas within organizations, with an emphasis on the actions and practices of individuals aimed at conveying and transforming those ideas (Czarniawska, 1996). Second, also in line with Callon's model of translation and Greenwood et al.'s model of institutional change, the paper assumes a processual view of NWoW as being a change project made of four analytical "moments" which may overlap with each other. In the following section, an empirical account of the legitimation process of the NWoW project at BIC is introduced.

\section{Legitimizing NeW Ways OF Working: the CASE OF BIC}

\section{From precipitating iolts to problematization}

The idea that organizations inevitably face specific events (or "precipitating jolts") that cause disruption and compel them to adapt is central to the model of Greenwood et al. (2002). In the case of BIC, the imperative of relocating the company's activities is an example of such a precipitating jolt. BIC's two most important buildings were located in the country's capital - the headquarters hosted approximately 1500 workers and a second building encompassed about a thousand employees. Those buildings, however, were not owned by the company, but were subject to a rental contract which would come to an end in the following years. Furthermore, because the buildings were constructed in the sixties, they had to be renovated: the lease contract could not be renewed. The top managers of BIC, then, had little choice: a relocation was practically unavoidable. The material necessity to relocate a part of the company's activities - a perfect example of a "precipitating jolt" in Greenwood et al.'s model (2002) - prompted the strategic reflexion which was initiated in 2012, with a planning horizon of five years until the expiry of the lease agreements.

Yet, organizational life is full of precipitating jolts which do not necessarily nor mechanically trigger organizational change; what matters, as both Callon (1986) and Greenwood et al. (2002) have pointed out, is how actors seize those moments and what they decide to do with them. On this point, Greenwood et al. (2002, p.72) ultimately acknowledge the crucial importance of building "a convincing problem" that calls for the organization to change. Such "problems" are socially constructed through a process that the sociology of translation has termed "problematization", a process which is intrinsically political - as the definition of what those problems should entail involves rational actors who negotiate, justify their decisions, contest each other, make alliances and defend their own interests (Callon, 1986).

In the case of BIC, although strategic discussions about the relocation initially took place in the executive committee, the task of problematizing was primarily handled by a dedicated working group. 
Four actors - the HR Director, a strategic HR advisor, a change manager, and a business transformation consultant - were formally entrusted with the task to carry out explorative studies in order to push the project forward:

"We made analyses, we conducted studies, we invited people, we built project drafts. We thought, what do we want to be, not in five years, but in twenty?" (HR strategic advisor)

Additional elements were progressively funneled into the discussions by this working group, which contributed to transforming the objective constraint to relocate into an "opportunity". A first issue brought to the table was related to mobility options and to the geographical location of the building. The headquarters were situated on the periphery of the capital, in a zone poorly served by public transportation, which caused frustration for many workers who wasted time commuting. As such, the geographical location of the new building was quickly recognized as a key strategic variable. Meanwhile, explorative studies were being performed on the construction market in and around the city and provided financial insights to the company regarding the relocation costs. As several field actors put it, "the square meter in the capital is extremely expensive" (HR Director). By reducing the building size and optimizing space use, it was argued that the company could definitely cut costs and save money while operating just as well. Third, very early in the transformation process the new building was thought of by the HR director as a potential showcase for BIC and as a key element for the company to "attract new talents" and to "reach the new generation on the labor market" (HR director). A vast reflection regarding the future relationship between BIC and its customers was undertaken as well: the adequacy of BIC's products in an "ever-changing world" and the "clarity of (our) range of services" (HR strategic advisor) was a fourth point of debate within the working group. At the same time, explorative studies on emerging communication technologies were also conducted. As the HR strategic advisor explained, "recent technological developments allow us to do much more than what could be done five years ago" (HR strategic advisor). The working group performed a comparative analysis of a range of tools - such as videoconference systems, messaging software and virtual boards. A final component of the strategic reflection of the workgroup was related to the culture of the company. What working at BIC would mean, the working group argued, had to be rethought. That would entail radical changes in managerial practices, in the company's vision and goals, and in the foundational principles of the corporate culture.

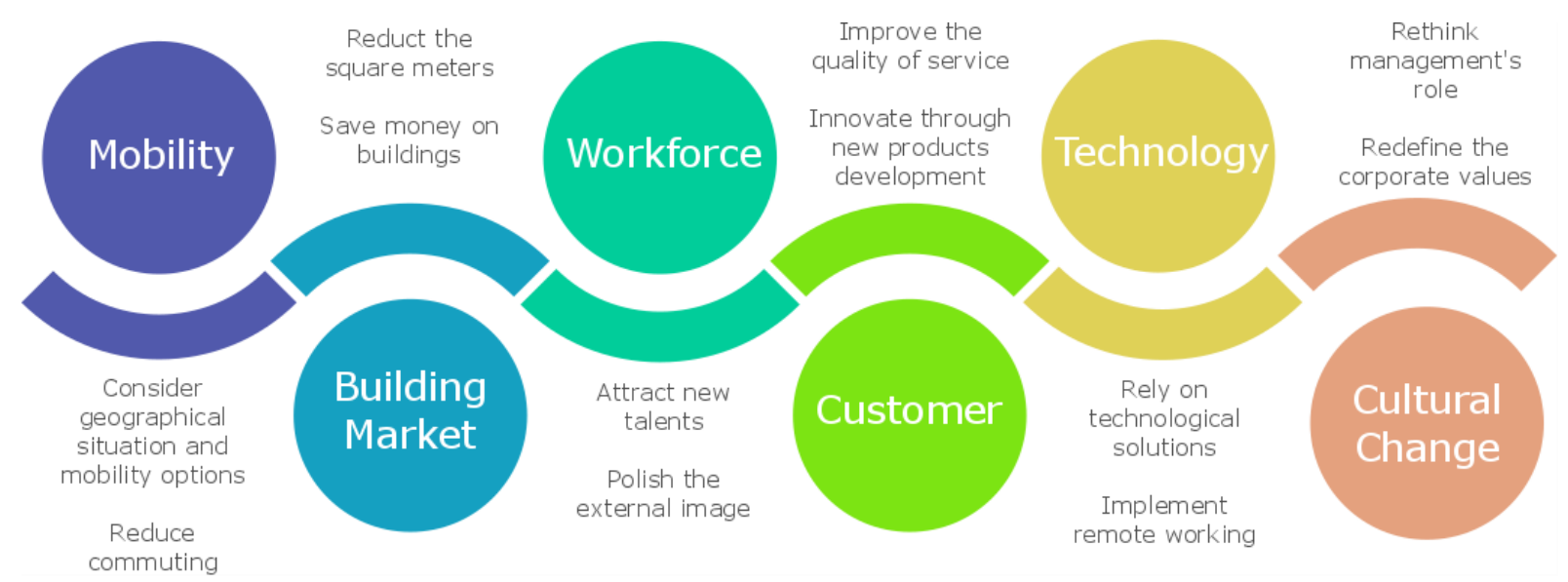

Figure 1 -Summary of the problematizing elements identified by the exploratory working group 
Through such problematizing work, the working group went beyond the initial need to relocate and became able to build strong narratives to argue for fundamental institutional change, reframing the project as being first and foremost cultural rather than material:

"There was a red wire all along, and it was our HR Director. She defined the transformation project as being a cultural project, and she did not deviate one iota from her original vision (...) We could have said, in five years, we will move to another building. This is not what happened. We said, 2017 will be a year of cultural change, and incidentally, we will move out". (HR strategic advisor)

The HR Director played a pivotal role in this framing process, acting both as an executive committee member and as a sponsor of the working group. Progressively, the relocation constraint no longer appeared to be the core issue, and was rather depicted as part of a much wider problematic "designing [the BIC] of the future" (HR Director). The initial, material constraint - a building that was too old and a company that needed to be relocated and reconfigured - was concealed by key actors under discourses promoting a "cultural change".

\section{From pre-institutionalization to interessement}

So far, the four members of the working group were, under the lead of the HR Director, the main actors in charge of the problematization work. However, their early conclusions did not immediately lead to tangible and concrete actions for the company to undertake. Greenwood et al.'s third stage refers to "pre-institutionalization" to characterize the progressive elaboration of "technically viable solutions" that can be implemented locally by organizations (2002, p. 60). In the case of BIC, this process could hardly take place exclusively within the working group for at least two reasons. First, the actors in the group did not always have the appropriate skills and knowledge to assess the viability of potential solutions across a series of dimensions - such as technical, technological, or financial feasibility. Second, and most important, such decisions required the formal approval of the local deciding authority, namely, the executive committee. As a consequence, the pre-institutionalization stage could hardly occur without expanding the actual scope of the actors involved in the process.

Expanding the project's participatory scope also meant that the problematization could not remain indefinitely in the hands of the working group and had to be submitted to its constituent entities - a stage called "interessement" in the sociology of translation (Callon, 1986, p. 8). The actor of the problematization - the working group - had to make sure that the executive committee would align with its interests and vision: as such, the group had to persuade, to convince and to recruit allies in order to grow stronger (Akrich et al., 2002). Interessement has been described as a crucial phase of the innovation processes, since the refusal of newly committed actors to adhere to the problematization may result in the failure and the abandonment of a project (Akrich et al., 2002; Hansen and Clausen, 2017; Sarker et al., 2006).

As a matter of fact, the four actors of the working group were fully aware that the project's success would ultimately rely on their ability to gain support from the management committee, whom they "had to convince and embark through a six-month co-construction journey" (HR strategic advisor). They deployed two kinds of strategies to "convert" the executive committee: one of persuasion, and one of inspiration. Persuasion work mainly occurred through the development of a "convincing business case" (HR Director). This business case acted as a device of interessement (Callon, 1986), that is, as a tool that created convergence and stability around the issues identified by the working group. As the HR strategic advisor explains, "we had to prove with numbers that if we worked this way, we would reduce 
our operating costs". The business case was described as "self-explanatory" (HR strategic advisor), as multiple sources of savings - mainly on square meters due to the relocation to a smaller building, but also on maintenance, equipment, printing, and telephony - were expected to reduce the company's running costs by at least $20 \%$. The transformation project appeared very early as a way to cut costs by shrinking the necessary workspace. What made the persuasion work difficult was not the financial business case, which was "rational and undeniable" (HR strategic advisor). Rather, it was the whole cultural package that the working group was eager to promote:

"We had three lines of argument. One, this will be a project in which we save money. That was, in fact, the easiest part to demonstrate. Two, if we do that, the commitment and the motivation of our employees will rise. And three, as a consequence, their productivity will rise too. We had a lot of questions on those last two points, and it was not something that was easy for everyone in the executive committee to understand... Because it was at odds with the company's culture." (HR strategic advisor)

As the persuasion work was not sufficient in selling the transformation project to the executive committee, the working group took the decision to complement their approach with inspirational work. Such inspiration would mainly come from the organizational field of BIC, as the working group began to identify and to contact experts to meet, companies to share with and networks to join. The most interesting result of these benchmarking activities may be the identification and the adoption of a label for the transformation project - New Ways of Working (NWoW) - a label that explicitly refers to a defined set of changes (workspace rationalization, flexible work practices supported by technological innovations, and cultural transformations) while remaining broad enough to allow further customization of the project by BIC. A sample of "inspiring NWoW projects" (HR strategic advisor) was selected within the bancassurance field and beyond and turned into internal case studies". Such case studies would, for example, show that "[this company] had succeeded in reducing its office space by 30\%" or that "89\% of employees found their company more attractive now that it had implemented a NWoW project"6. Later on, "inspirational visits" were organized and meetings were arranged, as "there is nothing more powerful than having your CEO discussing with another CEO, because they speak the same language" (HR Director).

The persuasion work performed by the working group aimed to convince the executive committee that a transformation project over and above an ordinary relocation was the right thing to do. At the end of a six-month period of preparation and conception, the executive committee gave its consent to carry on, as BIC's CEO decided to endorse the project:

"Our CEO was not immediately convinced (...) He had a billion questions, ranging from strategic to pragmatic ones. And after six months, he finally said to the [executive] committee, now, we will not ask further efforts from the team, we have enough information, the real question is, do we believe in it, or not? He used the words: "this is an act of faith". Then, the committee collectively took the decision to go on with the project." (HR strategic advisor)

The interessement process, however, did not end there. A last step for the working group was to gain the official approval of the head office of the global group to which the national insurance company belongs - hereafter named GGIC - which must approve every national project exceeding a defined budget:

"Convincing [GGIC] was difficult. We were not sure we could succeed, not at all. We received in fact very few questions on the business case, much more on the cultural change. Are you sure that people 
will accept not having their own desk, even managers? You plan to have seven desks for ten employees, are you sure it will be enough? (...) Our strength was to come with both our HR Director and our CEO (...) They ended up saying, give it a try, and we will see..." (HR strategic advisor)

This step was more intricate as GGIC's board of directors had not been involved at all in the six-month "journey" of inspiration and persuasion that had been key in obtaining the consent of the executive committee of BIC. The quotation above illustrates the political dimension of the interessement process, as the support gained from BIC's CEO seemed to have been heavily weighted in favor of the working group. Although shareholders' concerns with the project were serious, they eventually gave their go-ahead to the transformation project.

\section{From theorization to enrolment}

From there, substantial efforts were made by the working group to build common understandings and narratives of the change to come. Greenwood et al. (2002) have well emphasized the crucial role of theorization in the legitimation of new practices. Theorization can be seen as a discursive strategy that consists in producing accounts which simultaneously define a threat to the organization, a solution to respond to that threat, and a strong rationale justifying this solution (Greenwood et al., 2002, p. 60). Theorization offers simplified representations of the problems at hand, hence facilitating the diffusion and adoption of discourses in the organization (Greenwood et al., 2002).

It is worth noting that BIC's working group had already performed a sort of early theorization by labeling their project as being a "New Ways of Working" approach, hence referencing to external, "inspiring" and relatively similar projects. The working group pushed the theorizing and framing exercise further by stating that "New Ways of Working" entailed three key poles in interaction, namely the "Bricks", the "Bytes", and the "Behaviors". The term "Bricks" was primarily related to the creation of a "dynamic, open, flexible and activity-based" workspace; the "Bytes" designated the deployment of new digital tools to support remote working; finally, the "Behaviors" referred to the "cultural transformation" that the company had to undertake. Such principles offered cognitive models of action, simultaneously exemplifying how the transformation project should be understood and delineating its perimeter.

Interestingly, the "3Bs" were not spontaneously generated by the local actors. Rather, the theorization around Bricks, Bytes, and Behaviors, which had already been used in other companies, seemed to be, in the case of BIC, a somewhat passive replication of existing New Ways of Working projects. Through the inspirational work performed upstream, the working group had already established a close relationship between New Ways of Working and those "3Bs":

"It is a proven approach that works very well. We saw that in the Netherlands. In such projects, you always proceed this way." (External consultant)

While we looked at the "3Bs" as the primary way of theorizing, further instances of theorization strategies could be observed at BIC. For example, within the "Behaviors" team, a charter of four principles constitutive of the NWoW project - trust, autonomy, results-orientation, and connectivity was established. Those principles would later be turned into "the four pillars of the Behaviors journey"7, structuring the training plan that employees and managers would later follow. Although inspiration was probably drawn from other NWoW projects (which have featured comparable behavioral charters), this second form of theorization turned out to be much more "homemade" than the " $3 \mathrm{Bs}$ ", 
which were simply replicated from existing cases. This theoretical model became a much needed cognitive framework enabling the project members to align as well as to ensure consistency among the various project groups over time:

"At some point, there was a need to describe what "Behaviors" meant. We wanted to acquire a common language across the project teams (...) More importantly, teams began to change: some people left us, others joined us. So we had to agree, when we say "NWoW", what do we really mean?" (HR strategic advisor)

The main goal of the theorization work was to ensure that the project would gain support from the various organizational actors. The sociology of translation uses the term "enrolment" to define further operations expanding the number of actors involved in the change process (Callon and Law, 1982; Callon, 1986). As the outcome of the strategic negotiations described in the previous sections, two teams dedicated to implementing the project were formed. The first one, named "Project 2017", would take in charge the conception and the execution of the transformation project; the second one, "Steerco 2017", would act as a junction (steering committee) between the first team and the executive committee. The initial working group was dissolved; the HR Director took a step back, remaining in the executive committee; the HR strategic advisor became a member of the steering committee; the change manager and the external consultant joined the "Project 2017" team.

\section{Executive Committee}

\section{Steering Committee}

\section{Project 2017}
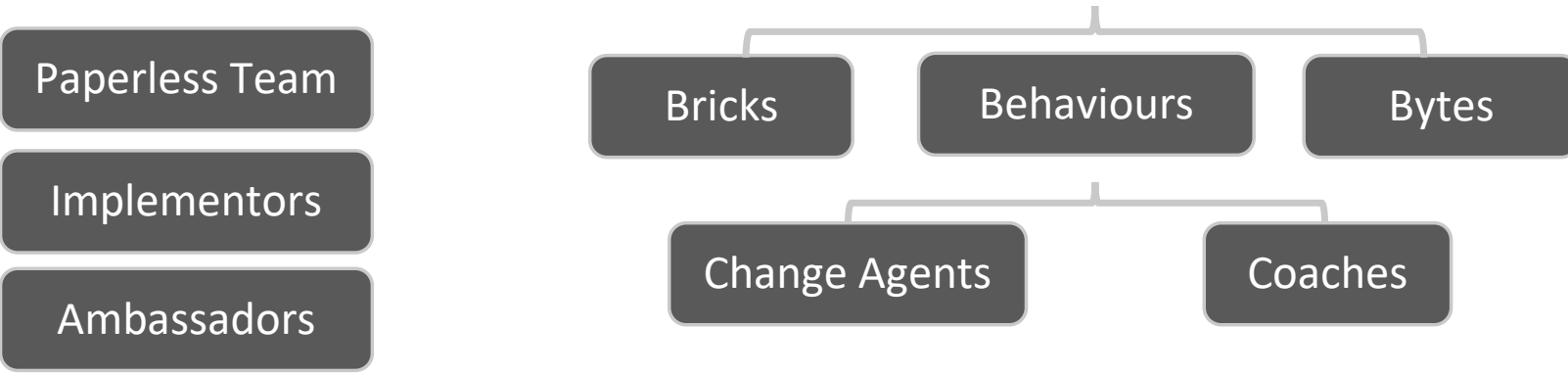

Figure 2: Overview of the transformation project's enrolment structure

Based on the "3Bs" theorization, significant machinery was progressively put into place to give substance to the transformation project. Figure 2 illustrates how the enrolment process resulted in an expanding project team, as new actors were enrolled to lend support and to participate in the change design and implementation. Simultaneously, the "3Bs" were used to delineate three specifics fields of expertise that were deemed relevant to carry out the transformation project. The "Bricks" team encompassed designers and building specialists; the "Bytes" team gathered IT specialists; the "Behaviors" team was made of HR specialists and change managers. Enrolment strategies did not stop there. As Figure 2 illustrates, numerous groups of actors were formed to help with the development and deployment of the project. ${ }^{8} \mathrm{~A} 9$-month training plan was put into place for all employees and managers, split between 6 months of preparation - which included a kick-off day, theoretical and "deep dive" sessions, technological workshops, and "master classes" - and 3 months of follow-up and transition - consisting of team meetings, flexible workplace simulation and evaluations. An interactive 
platform was launched by the Bytes team so that every employee could raise questions that would be processed by the project teams. A "network" of internal "ambassadors", whose role was to convey information from project teams to workers and vice versa, was composed on a voluntary basis. Throughout the process, particular attention was paid to the team managers to ensure that they would follow and endorse the NWoW project:

"Ultimately, what we are trying to accomplish here can only work if team managers are buying it. Their support is of prime importance for the NWoW to come alive and last through time." (Behaviors team member)

The legitimation process of the NWoW project at BIC reached a turning point as the relocation occurred. All the work that had been done for months was aimed towards the particular moment of the relocation and the confrontation of employees with their new workspaces. Once the relocation was complete, each employee was able to assess whether the new workspaces effectively responded to their needs. Space could be visited and lived in, allowing the actors to deploy various forms of appropriation and contestation ${ }^{9}$.

\section{From mobilization to diffusion}

The last stage of Callon's model of translation (1986) - named "mobilization" - describes the attempts by some actors to establish themselves as worthy representatives of their peers and to claim the right to speak about the project on behalf of others. At BIC, convinced spokespersons emerged to promote the benefits of New Ways of Working within and beyond organizational boundaries (Akrich et al., 2002). The designation of "motivated ambassadors" among the workers, whose role was to liaise between project teams and operational teams, was a first illustration of an internal mobilization process. It is likely that these ambassadors, who volunteered on the one hand, and were also inscribed into organizational interdependencies favoring their participation on the other hand ${ }^{10}$, became more supportive of the transformation project than the employees they claimed to represent. Employees and middle managers were further invited to submit stories of their own experience in the new workplace; actively diffused through intranet networks, the stories were another way for the project teams to defend the validity and merits of their approach, through a careful selection of those who would be given voice and visibility. Some middle managers also went beyond the project teams' expectations in their work practices, for instance with regard to the organizational arrangements suggested by the NWoW environment:

"I realized, now you can work at home two days per week, which is a step in the right direction. But can you do some sports in the morning, come to the office at eleven, and leave around seven in the evening? Or can you leave the day at three, pick up children from school, and resume working later at home? They [the project teams] did not go that far, but such flexibility is part of the philosophy of NWoW. So with the team, we had a meeting, we reached an agreement, and we launched a pilot project of our own." (Team manager)

Later, surveys carried out within the company showed that "76\% of the employees would now recommend NWoW to their colleagues" and that "72\% say that the company has become more attractive for its employees as a result of $\mathrm{NWoW}^{\prime 11}$. Such survey results also in a sense acted as intermediary representatives for the employees, including those who did not respond. That the transformation project was a success, and that both managers and employees actively supported it, 
became, to use Callon's wording, "credible and indisputable propositions"12 (1986, p. 14), concealing local resistances and tensions.

The model of Greenwood et al. (2002) focuses on dissemination and diffusion processes that exceed organizational boundaries. At the time, BIC was among the first companies in Belgium to implement a NWoW project, and as such, the company progressively began to attract attention from a variety of interested and curious companies. BIC's transformation project was promoted in the press through several contributions from the project managers to the press, notably through a "workplace showcase" published in a specialized magazine. BIC's HR director, who was seen as the one who had turned the relocation process into a successful cultural project, was later nominated "HR Manager of the year" a prestigious award in the Belgian HR field - due to her investment in the transformation project. Tours of the new building were organized for several external companies, some of them being BIC's customers, which BIC's CEO would "attend when possible" (HR strategic advisor). As one HR advisor explains, the project leaders decided to "offer moments of inspiration similar to the ones we benefited from partners such as Rabobank". Surprisingly, trade unions representatives also played a role in defending the transformation project to the outside world:

"Nowadays we organize meetings between our representatives and representatives from other companies. I still remember the first time I heard my trade unions explaining to other representatives why working at home is a good thing. What an upside-down world, right? " (HR strategic advisor)

The transformation project also strengthened $\mathrm{BIC}^{\prime} \mathrm{s}$ credibility with the international insurance group they belong to. As one Project 2017 team member predicted shortly after moving to the new building, "the others are going to copy us". Three years after the relocation, it seems that the transformation project has indeed acquired a strong legitimacy within the group. The general director of the group publicly encouraged other national offices to "follow the example of $B I C$ " in a three-minute video explaining why he believed in their transformation project. As a communication manager explains, "delegations from nearly all offices came to visit us, and we operate in more than fifty countries, so it is far from insignificant". In that regard, BIC progressively became a trendsetter of NWoW within the group, within its organizational field - as the first insurance company in Belgium to implement such a transformation project - and beyond - as several companies from other fields participated in visits to the new building.

\section{FINDINGS}

The case illustrates that New Ways of Working are best understood as projects of change that require purposeful work performed by key actors in order to become legitimized and legitimate in organizational contexts. The integrated framework used in this study reveals that the specificity of NWoW projects lies in a set of distinctive elements: a relocation, a project of cultural transformation, a business plan, a pseudo-theorization around Bricks, Bytes and Behaviors, a structuration of project teams around these " $3 \mathrm{~B}$ ", and efforts deployed to promote the project beyond organizational boundaries. These elements are the result of four operations of "translation" (Callon, 1986), which are summarized in Table 3 and appear to be constitutive of the legitimation process of NWoW projects. 


\begin{tabular}{|ll|}
\hline $\begin{array}{l}\text { STAGE 1 } \\
\text { FROM PRECIPITATING JOLTS TO } \\
\text { PROBLEMATIZATION }\end{array}$ & $\begin{array}{l}\text { Translating short-term material constraints into a strategic } \\
\text { organizational change project }\end{array}$ \\
\hline $\begin{array}{l}\text { STAGE } 2 \\
\text { FROM PREINSTITUTIONALIZATION } \\
\text { TO INTERESSEMENT }\end{array}$ & $\begin{array}{l}\text { Building a viable business plan in order to gain support from top } \\
\text { management and trigger an irreversible decision to commit to a } \\
\text { change project }\end{array}$ \\
\hline $\begin{array}{l}\text { STAGE } 3 \\
\text { FROM THEORIZATION TO }\end{array}$ & $\begin{array}{l}\text { Transforming compelling discourses around "NWoW" into an } \\
\text { organizational machinery attributing roles and responsibilities }\end{array}$ \\
\hline STROLMENT & $\begin{array}{l}\text { Fostering the rise of legitimate spokespeople who make it possible } \\
\text { for the external world to view the company as having successfully }\end{array}$ \\
FROM MOBILISATION TO & implemented a "NWoW" project \\
\hline DIFFUSION &
\end{tabular}

Table 3: Key translating operations constitutive of the legitimation process of a NWoW project

Initially, a constraint to relocate becomes overshadowed by a project of cultural transformation and is turned into a business case. Once the business case is validated by the executive committee, the decision to commit to a NWoW project is no longer questioned, and project teams are established. The complex exploratory work initially performed by the working group is then replaced with compelling discourses around the "3Bs". Eventually, the company itself becomes reduced to a set of success stories in which the struggles, issues, and failures of the change process are made invisible. What is left to be seen - a NWoW project in an insurance company - is the product of a complex process of legitimation that entailed a problematizing work around a relocation imperative, an interessement phase made up of persuasion and inspiration moments, a theorization effort around "3Bs" that led to the creation of project teams, a relocation to a new building and a mobilization process involving legitimate spokespeople speaking in the name of the organization.

\section{DISCUSSION}

\section{New Ways of Working projects as legitimation processes}

These findings question and expand the existing, albeit thin literature on New Ways of Working. As a reminder, available studies have mostly been interested in the outcomes and effects of NWoW projects (e.g. Demerouti et al., 2014; Gerards et al., 2018; Laihonen et al., 2012). A dark spot in these studies is that they do not explore nor explain how the ideas underlying the NWoW fashion have been problematized locally and promoted as acceptable and desirable for the organizational members. As a consequence, in the absence of empirically-grounded analyses of NWoW projects in the making, insights relative to NWoW design and implementation have essentially remained of normative and prescriptive nature. For instance, Peters and colleagues state that "NWoW implementation should be centered on the employees themselves" (2014, p. 284), while Brunia and colleagues plead for the "avoiding or reduction of resistance to change" for a "successful implementation" of NWoW (2016, p. 32). In contrast with these prescriptive discourses, the present paper illustrates that NWoW is a fragile 
construct resulting from a legitimation process, involving a variety of actors who deploy considerable efforts to turn NWoW into an accepted element of the organizational life.

Moreover, the paper also suggests an original and grounded conceptualization of New Ways of Working as being projects of organizational change underpinned by a process of legitimation structured by four decisive moments (summarized in Table 3). Whereas authors concur on the fact that defining NWoW is a complicated task (De Leede, 2017; Kingma, 2018; Kok et al., 2015), we argue that this task has so far been taken rather lightly. For instance, it has been suggested by Kok and colleagues (2015) to define NWoW as being made of Bricks, Bytes, and Behaviors. In line with Kingma (2018, p. 2), the paper argues that these remain "consultancy terms", and that they are local constructs or pseudo-theorizations of the local actors that are deployed to make sense of a strategic decision (to initiate a change project) as well as a way to attribute role and responsibilities. More generally, as pointed out in the literature review, studies of NWoW are being hampered by the multiplication of content-oriented or essentialist definitions of the object of study. The suggestion developed in this paper is to view NWoW as projects of organizational change involving a process of legitimation, in the course of which the field actors resort to the "NWoW" fashion and label. In this perspective, whether such projects entail or should entail empowerment, trust and teleworking (Peters et al., 2014), flexible spatiotemporal practices, collaborative work practices, and participative management (Ajzen et al., 2015), or work-time flexibility, spatial flexibility and new media technologies (Ten Brummelhuis et al., 2012), is a question answered by the field actors themselves.

\section{Towards an integrative framework for researching legitimation}

While the primary objective of the study was to explore the process of legitimation in a NWoW change project, the paper also has theoretical implications related to the combined use of the sociology of translation and the institutional work theory for understanding legitimation processes. In the introduction of the paper, we postulated that an integrated framework derived from the models of Callon (1986) and Greenwood et al. (2002) may be particularly well suited for conducting in-depth analyses of legitimation processes. Bringing together these two specific models was, however, a novel experience - the closest attempt being a conference paper written by Leca and colleagues (2006). We argue that the present study illustrates how the integration of these two models may act as a powerful analytical tool to grasp how a change project progressively becomes legitimized in organizational discourses and practices. To back up this claim, let us examine four benefits of integrating both models into a single framework: a more comprehensive view of legitimation (1), stages of analysis that complement each other (2), additional conceptual tools to account for legitimation processes (3), and an inclusion of discursive and material strategies of legitimation (4).

First, the integrated framework suggested in the paper brings together two distinct conceptions of legitimation. Legitimation, in the perspective of Greenwood and colleagues (2002), refers to the process through which a given innovation (or a management fashion) gradually acquires viability and desirability. The empirical study indeed focuses on the adoption process of NWoW and on the social construction of an "imperative" to change. By contrast, the model suggested by Callon (1986) primarily looks into the creation of networks around problems, and the subsequent transformations (or translations) of these problems over time. According to the sociology of translation, legitimation allows specific actors to "grow" and to speak on behalf of others, which confer them "greatness and longevity" (Callon \& Latour, 1981, p. 284). The case of BIC illustrates how specific problems (an imperative to relocate) and solutions (a "NWoW"-labeled project of "cultural transformation") are 
progressively turned into unquestioned and natural arrangements, and how specific actors (such as the exploratory group and the HR Director) manage to acquire legitimacy in the process. Building on these two perspectives, the integrated framework suggested in the paper results in a more comprehensive view of the legitimation of New Ways of Working, in which the actors, the problems and the translation process are given equal analytical attention.

Second, the stages suggested by Greenwood and colleagues (2002) and Callon (1986) respectively do not exactly match nor overlap. What our analysis illustrates is that each model fills in the gaps of the other. For instance, the process through which precipitating events (an imperative to relocate) will generate deinstitutionalization (a reconsideration of the existing "way of working") in the model of Greenwood and colleagues (2002) is best understood as being a problematization moment (turning a relocation into a transformation project). To take another example, the theorization around the " $3 \mathrm{~B}$ " usefully explains how the enrolment of the project teams occurred. The integrated framework allows for a more thorough understanding of legitimation processes than the two models taken separately. This observation is related to our third point, which is that both models draw the attention of the researcher on distinctive empirical realities. Precipitating jolts, technically viable solutions, theorizations, and diffusion, are specific conceptual tools offered by the model of Greenwood and colleagues (2002). The sociology of translation emphasizes the social construction of problems, the creation of alliances, the expansion of the actors involved in the process, and the designation of spokespersons as key moments of legitimation processes. Bringing these concepts together resulted in a more detailed and faithful account of the legitimation process in the case of BIC.

Finally, the institutional work and, by extension, the model of Greenwood et al. (2002), is primarily interested in discourses and discursive strategies as means of generating legitimation (Lawrence \& Suddaby, 2006; Perkmann \& Spicer, 2008). In their study, Greenwood and colleagues refer to the "legitimating discourse" to explain how institutionalization and theorization occur (2002, p. 74). For its part, the model of Callon (1986) leaves room for material strategies of legitimation: the business plan appears to be a central interessement device, and the new building itself materializes and stabilizes what NWoW means. As the present case illustrates, both discourses and materiality play a central role in the design and implementation process of NWoW, and the integrated framework encompasses both kinds of legitimating strategies.

In sum, the combination of these two models of organizational change and their underlying conceptions of legitimation allows the analysis to simultaneously illustrate how a management fashion - New Ways of Working - gains viability in an organizational context, while also allowing to retrace the transformations of the problems and actors involved in the process. The integrated framework developed in the paper brings two conceptions of legitimation together, is enriched by a multi-stage analysis and the mobilization of conceptual tools coming from both research on institutional work and the sociology of translation, and allows to account for discursive and material strategies of legitimation. At this point, the present study indicates that such a framework is indeed appropriate for studying legitimation processes of NWoW projects. The framework would require further testing in order to assert whether it might possibly be generalized to other, similar research objects. Theoretical contributions on the paradigmatic congruence of the models of Greenwood et al. (2002) and Callon (1986) would also contribute to strengthen or assert the limitations of the framework. Therefore, we plead for further attempts to articulate insights coming from these two theoretical approaches. 


\section{Conclusions}

The paper offers a critical perspective on a management fashion that has so far received little attention from scholars. A processual approach to NWoW is developed, in which NWoW is conceptualized as a change project that undergoes a process of legitimation and eventually becomes an accepted arrangement of organizational life. How such transformation projects emerge and become implemented within organizations are questions that have been disregarded in existing studies on NWoW. Based on a grounded and longitudinal analysis of a case study, the paper identifies a fourstage framework that characterizes legitimation processes underlying NWoW change projects. The framework suggests four operations of translation that are necessary for a NWoW project to become accepted as legitimate: translating material constraints into strategic opportunities; translating strategic opportunities into a quantitative business plan supported by the top management; translating compelling discourses around "NWoW" into an organizational machinery; and translating a transformation project into discourses of unequivocal success, conveyed by legitimate spokespeople both within and outside the organization.

The paper has implications for future research on NWoW as well as for professionals. Recognizing the central role of actors who perform legitimation work, the paper suggested four operations of translation constitutive of NWoW projects. While these elements were decisive in the design and implementation of a NWoW project in this specific case study, further studies are needed to determine whether the proposed framework may serve as an adequate and generic framework for similar cases. The case also questions the validity of "post-occupancy" kinds of approaches to NWoW, which do not reflect on the mechanisms underlying the adoption and design processes of NWoW within organizational contexts. Instead of pursuing investigations of the "outcomes" of NWoW, we would argue for further attempts to shed light on the motives underlying the adoption of the NWoW management fashion in organizations, through processual approaches of NWoW projects in the making. Lastly, the findings of this study should draw the attention of managers (or of anyone interested in NWoW projects) on key moments punctuating the implementation process: the local construction of convincing problems, the endorsement of the project by the deciding authorities, the elaboration of eloquent and efficient theorizations, and the adequate selection of designated spokespeople. More broadly, building legitimacy appears essential for NWoW to become an accepted element of organizations. The paper suggests, therefore, that professionals involved in NWoW project should account, in their practices, for the legitimation process and work underlying NWoW design and implementation.

\section{Notes}

${ }^{1}$ See for example the white paper by Gates and Rasmus, entitled: "Digital Workstyle: The New World of Work" (2005) or the book by D. Bijl, entitled: "Journey Towards the New Way of Working: Creating Sustainable Performance and Joy at Work" (2011).

${ }^{2}$ With the successive books of Veldhoen (2005), Baane et al. (2010) and Bijl (2011) among others.

${ }^{3}$ We initially contacted a total of eight team managers in the company, who were chosen on the basis of the teams occupying the building. Five of them agreed to be interviewed, and three of them further gave their consent for their employees to be contacted. We then interviewed all the employees that agreed to meet with us in the three different teams that are the Legal Protection Production, the Legal Protection Claims, and the Life Insurance Claims. 
${ }^{4}$ Collecting data through three successive rounds and with various actors of the organizations (top managers, middle managers, project team members, and employees) allows to cross-check the validity of most of the findings. It should be noted, however, that the data from Round 3 was mostly collected among the leading actors of the HR department. While this was justified by the fact that the NWoW project at BIC was primarily designed by a working group led by the HR Director and gathering HR Advisors (as the empirical narrative illustrates), the relative absence of other key actors in our sample (such as the CEO of that time, who has now left the company) may be a limitation of the study.

${ }^{5}$ Inspiration was mainly drawn from two Dutch banks and two other forerunners in the adoption of NWoW projects at the time - a large IT company and a Public Federal Service.

${ }^{6}$ Source: "BIC World of Work 2017: Vision phase", internal document.

7 Source: "The NWoW at BIC », internal document promoting the transformation project.

${ }^{8}$ Such groups included a specific "Paperless" team of four people whose aim was to reduce the use of paper in the company; "Implementers" who were assigned specific departments to supervise; "Ambassadors" who,

chosen among the employees, would play a pivotal role in information sharing between operational teams and project teams; "Change Agents" in charge of familiarizing teams with the newly defined organizational culture; and "Coaches" who would closely follow, listen and advise every middle manager concerned with the transformation project.

${ }^{9}$ Numerous behaviors of space contestation could obviously be observed once the relocation occurred. However, describing and analyzing those behaviors would exceed the scope of the present paper.

10 For instance, one of the ambassadors stated in an interview that she had "probably" been selected since she "got along with [her] director and knew one or two members of the project teams".

${ }^{11}$ Source : An internal survey called « Post NWoW status », carried out three months after the relocation.

12 Through what they called "reinstitutionalization", Greenwood et al. (2002, p. 61) also question the practices through which ideas become "uncritically accepted", "natural and appropriate" arrangements within organizations.

\section{REFERENCES}

Abrahamson, E. (1996), "Management Fashion", The Academy of Management Review, Vol. 21 No.1, pp. 254-285.

Ajzen, M., Donis, C. and Taskin, L. (2015), "Kaléidoscope des Nouvelles Formes d’Organisation du Travail : L'instrumentalisation stupide d'un idéal collaboratif et démocratique", Gestion 2000, Vol. 3, pp. $125-148$.

Akrich, M., Callon, M. and Latour, B. (2002), "The Key to Success in Innovation Part I: the Art of Interessement", International Journal of Innovation Management, Vol. 22 No. 2, pp. 187-206.

Assarlind, M., Eriksson, H., Gremyr, I. and Jakobsson , T. (2013), "Adopting new ways of working in small and medium-sized enterprises: Findings from interventions in 12 European companies", Total Quality Management and Business Excellence, Vol. 24 No. 8, pp. 945-958.

Baane, R., Houtkamp, P. and Knotter, M. (2010), Het nieuwe werken ontrafeld. Over Bricks, Bytes and Behavior, Assen: Koninklijke Van Gorcum.

Bergström, O. and Diedrich, A. (2011), "Exercising Social Responsibility in Downsizing: Enrolling and Mobilizing Actors at a Swedish High-Tech Company", Organization Studies, Vol. 32 No. 7, pp. 897-919. 
Bijl, D.W. (2011), Journey Towards the New Way of Working. Creating sustainable performance and joy at work, Par CC.

Blondeau, C. (2005), "Banque, assurance, bancassurance, assurfinance, lignes de partages: une spécificité française ? ", Entreprises et histoire, Vol. 39 No. 2, pp. 91-114.

Brunia, S., De Been, I., \& van der Voordt, T. (2016), "Accommodating new ways of working: lessons from best practices and worst cases", Journal of Corporate Real Estate, Vol. 18 No. 1, pp. 30-47.

Callon, M. and Latour, B. (1981), "Unscrewing the big Leviathan: how actors macro-structure reality and how sociologists help them to do so", in Knorr-Cetina, K., and Cicourel, A. V. (Eds.), Advances in social theory and methodology: Toward an integration of micro-and macro-sociologies, Boston: Routledge, pp. 276-303.

Callon, M. and Law, J. (1982), "On Interests and Their Transformation: Enrolment and CounterEnrolment", Social Studies of Science, Vol. 12 No. 4, pp. 615-625.

Callon, M. (1986), Some elements of a sociology of translation: Domestication of the scallops and the fishermen of St Brieuc Bay, in Law, J. (Ed.), Power, action and belief: A new sociology of knowledge?, London: Routledge and Kegan Paul, pp. 196-229

Czarniawska, B. (1995), "Narration or Science? Collapsing the Division in Organization Studies", Organization, Vol. 2 No. 1, pp. 11-33.

Czarniawska, B. (1996), "Travel of Ideas", in Sevón, G. and Czarniawska, B. (Eds.), Translating Organizational Change, Berlin: de Gruyter, pp. 13-48.

Czarniawska, B. (2003), "Constructionism and organization studies", in Westwood, R. I. and Clegg, S. (Eds.), Debating Organization: Point-Counterpoint in Organization Studies, Blackwell, Malden, pp. 128139.

Dacin, M., Goodstein, J. and Scott, W. (2002), "Institutional Theory and Institutional Change: Introduction to the Special Research Forum", Academy of Management Journal, Vol. 45 No. 1, pp. 4556 .

De Bruyne, E. and Gerritse, D. (2018), "Exploring the future workplace: results of the futures forum study", Facilities, Vol. 20 No. 3, pp. 196-213.

De Leede, J. (2017), New Ways of Working practices: Antecedents and outcomes, Emerald Group Publishing Limited.

Demerouti, E., Derks, D., Ten Brummelhuis, L. and Bakker, A. (2014), "New Ways of Working : Impact on Working Conditions, Work-Family Balance, and Well-Being", in Korunka C. and Hoonakker P. (Eds.), The Impact of ICT on Quality of Working Life. Springer Netherlands, pp. 123-141.

Demers, C. (2007), Organizational Change Theories: A synthesis. Thousand Oaks, CA: Sage.

Donaldson, L. (2001), The contingency theory of organizations, Sage.

Dowling, J. and Pfeffer, J. (1975), "Organizational legitimacy: Social values and organizational behaviour", Pacific Sociological Review, Vol. 18 No. 1, pp. 122-136. 
Garud, R., Hardy, C. and Maguire, S. (2007), "Institutional Entrepreneurship as Embedded Agency: An Introduction to the Special Issue", Organization Studies, Vol. 28 No. 7, pp. 957-969.

Gerards, R., Grip, A. and Baudewijns, C. (2018), "Do new ways of working increase work engagement?" Personnel Review, pp. 1-33.

Greenwood, R., Suddaby, R. and Hinings, C. (2002), "Theorizing Change: The Role Of Professional Associations In The Transformation Of Institutionalized Fields", The Academy of Management Journal, Vol. 45 No. 1, pp 58-80.

Hansen, P. and Clausen, C. (2017), "Management Concepts and the Navigation of Interessement Devices: The Key Role of Interessement Devices in the Creation of Agency and the Enablement of Organizational Change", Journal of Change Management, Vol. 17 No. 4, pp. 344-366.

Hwang, H. and Colyvas, J. (2011), "Problematizing Actors and Institutions in Institutional Work", Journal of Management Inquiry, Vol. 20 No. 1, pp. 62-66.

Kingma, S. (2018), "New ways of working (NWW): work space and cultural change in virtualizing organizations", Culture and Organization, pp. 1-24.

Kok, A., Esten, R. and Helms, R. (2015), "Knowledge sharing in the new world of work: Effects of the New Way of Working", Journal of Information Technology Services, Vol. 14 No. 2, pp. 315-335.

Langley, A., Smallman, C., Tsoukas, H. and Van de Ven, A. (2013), "Process Studies of Change in Organization and Management: Unveiling Temporality, Activity, and Flow", Academy of Management Journal, Vol. 56 No. 1, pp. 1-13.

Law, J. and Callon, M. (1988), "Engineering and Sociology in a Military Aircraft Project: A Network Analysis of Technological Change”, Social Problems, Vol. 35 No. 3, pp. 284-297.

Lawrence, T. and Suddaby, R. (2006), "Institutions and Institutional Work", in Clegg, S., Hardy, C., Lawrence, T. and Nord, W. (Eds.), Handbook of Organization Studies, London: Sage, pp. 215-254.

Leca, B., Gond, J., Déjean, F. and Huault, I. (2006), "Institutional Entrepreneurs As Competing Translators: a Comparative Study in an Emerging Activity", paper presented at the XVeme Conference Internationale de Management Stratégique, Genève.

Lounsbury, M. (2008), "Institutional rationality and practice variation: New directions in the institutional analysis of practice", Accounting, Organizations and Society, Vol. 33, pp. 349-361.

Mintzberg, H. (1979), The Structuring of Organizations, Englewood-Cliffs, NJ: Prentice-Hall.

Nubiola, J. (2005), “Abduction or the logic of surprise”, Semiotica, Vol. 4, pp. 117-130.

O'Mahoney, J., O'Mahoney, H. and Al-Amoudi, I. (2017), "How can the loggerhead sea-turtle survive? Exploring the journeys of the Caretta caretta using ANT and critical realism", Organization, Vol. 24 No. 6, pp. 781-799.

Pedersen, J. and Dobbin, F. (2006), "In Search of Identity and Legitimation", American Behavioral Scientist, Vol. 49 No. 7, pp. 897-907.

Perkmann, M. and Spicer, A. (2008), "How are management fashions institutionalized? The role of institutional work", Human Relations, Vol. 61 No. 6, pp. 811-844. 
Peters, P., Poutsma, E., van der Heijden, B., Bakker, A. and De Bruijn, T. (2014), "Enjoying New Ways to Work: an HRM-process approach to study flow", Human Resource Management, Vol. 53 No. 2, pp. 271-290.

Salancik, G. and Pfeffer, J. (1977), "Who gets power and how they hold on to it: A strategic contingency model of power", Organizational Dynamics, pp. 3-21.

Sarker, S., Sarker, S. and Sidorova, A. (2006), "Understanding Business Process Change Failure: An Actor-Network Perspective", Journal of Management Information Systems, Vol. 23 No. 1, pp. 51-86.

Sewell, G. and Taskin, L. (2015), "Out of Sight, Out of Mind in a New World of Work? Autonomy, Control, and Spatiotemporal Scaling in Telework", Organization Studies, Vol. 36 No. 11, pp. 1507-1529.

Suchman, M. (1995), "Managing Legitimacy: Strategic and Institutional Approaches", The Academy of Management Review, Vol. 20 No. 3, pp. 571-610.

Ten Brummelhuis, L., Bakker, A., Hetland, J. and Keulemans, L. (2012), “Do new ways of working foster work engagement?", Psicothema, Vol. 24 No. 1, pp. 113-120.

Veldhoen, E. (2005), The Art of Working. Den Haag: Academic Service.

Weick, K. (1979), The social psychology of organizing, Columbus, OH: McGraw-Hill Humanities.

Vink, P., Blok, M., Formanoy, M., de Korte, E. and Groenesteijn, L. (2012), "The effects of new ways of work in the Netherlands: national data and a case study", Work, Vol. 41, pp. 5081-5085.

Yin, R.K. (2011). Applications of case study research. Sage.

Zietsma, C. and Lawrence, T. (2010), "Institutional Work in the Transformation of an Organizational Field: The Interplay of Boundary Work and Practice Work", Administrative Science Quarterly, Vol. 55 No. 2, pp. 189-221. 